\title{
Characteristics of periodical movement of live squid (Todarodes pacificus) hooked on the branch line of a red sea bream long line
}

\author{
Myung Sung KoO, Munechika ISHIZAKI ${ }^{1 *}$, Suk Jong KIM, \\ Shigeru FUWA ${ }^{1}$ and Miguel Vazquez ARCHDALE ${ }^{1}$ \\ Department of Marine Industrial \& Maritime Police, Jeju National University, Jeju 690-756, Korea \\ ${ }^{1}$ Faculty of Fisheries, Kagoshima University, Kagoshima 890-0056, Japan
}

In Jeju Island, red sea bream is mainly caught by long line with a live squid as bait. The movements of artificial jigs in the fishery are supposed to be an important factor for catching the target organism as well as bait. To develop new fishing method for long line fishery, movements of the bait which was squid were tried to be characterized. In a water tank experiment, a live squid was hooked by a fish hook attached to a model long line. And then movements of squids in the water tank were recorded for 20 minutes by a video camera. Recorded movement of the squid was just periodically up-and-down moving, with a dominant frequency of $0.125 \mathrm{~Hz}$, and amplitude of $10.8 \mathrm{~cm}$.

Keywords: Amplitude, Characteristics of movement, Feeding behavior, Lure, Squid

\section{INTRODUCTION}

Within 1 mile from the coast of Jeju Island and approximately $10 \sim 50 \mathrm{~m}$ deep down in the sea, there are artificial reefs set up for the purpose of providing optimal environmental conditions for fish, and natural reefs created by volcanic activities.

For the species, which include red sea breams (Pagrus major), that are aggregated around the reefs, fishing is dependent on long line fishing gears instead of the bottom gill nets or other netting gears, due to the undulating seabed topography.
The process of catching fish with the long line is a simple method which waits for fish recognitions and bites on the bait hanging at the hook. Therefore, the phase between the fish's recognition of the bait and the visual stimuli from it is an important factor in catching the target fish. According to the empirical knowledge, it is known that using dead squids for bait does not attract red sea breams and using other popular baits such as kuruma shrimps and lugworms increases the possibility of capturing needless targets such as rockfishes. Due to the all reasons stated, live squids

*Corresponding author: ishizaki@fish.kagoshima-u.ac.jp, Tel: 81-99-286-4232, Fax: 81-99-286-4015 
become an ideal option for bait to catch red sea breams. The issue is that squids cannot survive when the water temperature is higher than 27 degrees (NFRDI, 2000; Lee et al., 1985). And those fishers cannot continue fishing during the summer period even when red sea breams are still available to fish around the reefs resulting from the higher water temperature for the squids.

Tamura (1952) conducted an experiment with sea basses (Lateolabrax japonicus) in a water tank in which he suggested that fish recognizes baits in two ways depending on the state of their movement. When the bait is moving, the fish perceives it as the bait, and when the bait is static, the fish perceives it as an irrelevant object. From this experiment, it is suggested that when a visual stimulus triggers the fish's feeding behavior for catching, fishing can be successful with a proper visual stimulus that can artificially substitute the movement patterns of live fish (Tamura, 1952).

The authors assumed that the results of the sea bass experiments could be applied for red sea breams and those fishers in Jeju Island area would be able to fish red sea breams without live baits if the movement patterns which can lure red sea breams are identified and a machine which can provide the moving patterns is developed. This would result in extending the currently limited fishing period to the summer.

In this research, the movement pattern of the live squid was assumed to be the optimal movement for catching red sea bream. Especially, the purpose of this study was to identify the characteristics and patterns of the movement of squids hanging from the branch line of a long line fishing gear.

\section{MATERIAL AND METHODS}

The experiments were carried out in indoor water tank located in the Marine \& Environmental Research Institute of Jeju National University from May 18 to 20,2009. The width, height and depth of the water tank were 360,175 and $175 \mathrm{~cm}$ respectively, and its width and heights of one of the observation windows at the front of the tank were 280 and $78 \mathrm{~cm}$. The water depth was set as $100 \mathrm{~cm}$, and its water temperature was 19.5 degrees. The

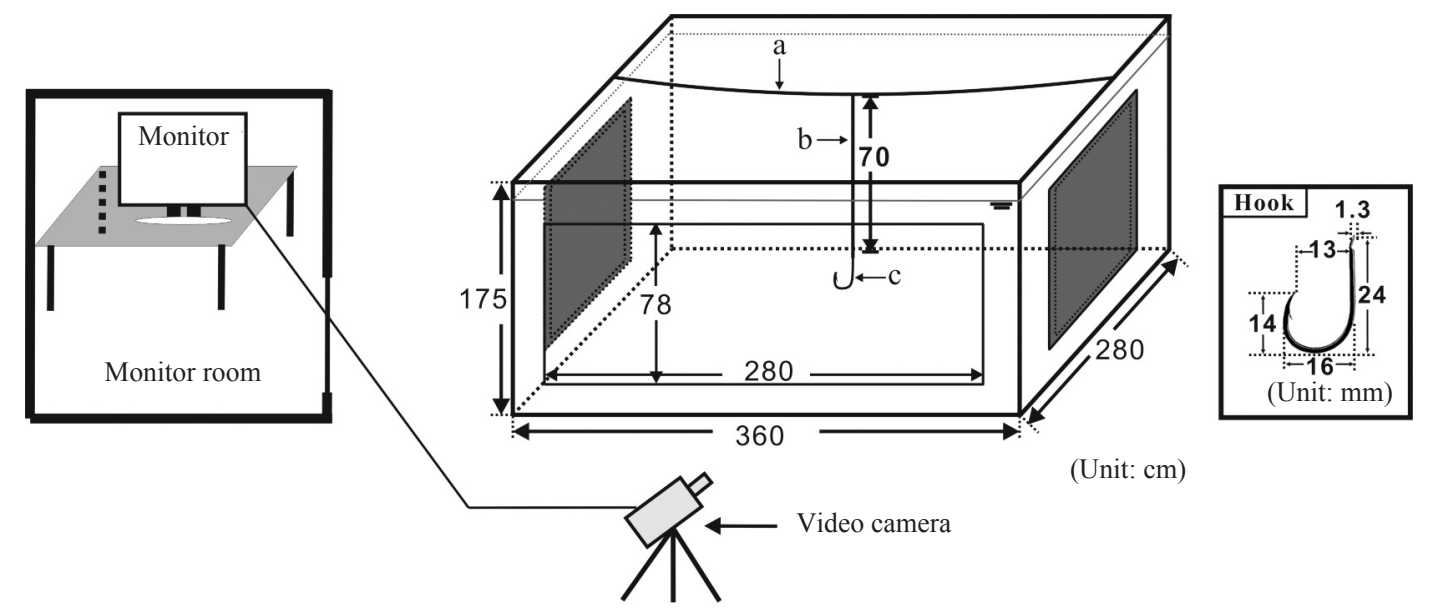

Fig. 1. Schematic drawing of the equipment used for the water tank experiment. Main line (a) and branch line (b) were hanged at the center of the water tank. The squids were hooked on the hook (c). The movements of the squids in the water tank were recorded by a video camera which was set in front of the water tank. 
light came through only one front window among the three windows. The schematic drawing of the model of a long line fishing gear in the water and experimental set up are shown in Fig. 1. The model used in this study was referred from the long line gear (main line ( $\mathrm{PP} \phi 4)$ : 50m, branch lines ( $\mathrm{PP} \phi 2)$ : 13, interval of branch line: $2 \mathrm{~m}$, hooks: 13 ) which was used for catching red sea bream by the Jeju Island fishing vessel named Dongah (6.97ton). The main line was a little longer than the width of the water tank and was set from left to right at the center at the top of the tank. The branch line was suspended vertically in the water from the middle of the main line. The hook was suspended at a $62.4 \mathrm{~cm}$ depth in the water.

Most of the long line fishing vessels targeting red sea bream around the Jeju area starts catching the live squids they will use as their bait for red sea breams with hand lines. After enough bait is obtained, they will start fishing from 22:00, and most finish before the sunrise. Moreover, since most red sea breams around this area are caught before the sunrise (Okada, 1965; Sudo et al., 1987), it is appropriate to observe the movement patterns of squids before sunrise. In this experiment, we put a live squid on the hook of the gear and observed the movement from 22:00 to 04:00 in the following day, before sunrise.

Though light entered the experiment room slightly, there was no change in the movement of the squid caused by this change of the intensity of the illumination and any change in the characteristics of the movements which would be affected by the long duration exposures. Therefore, we assumed that the swimming of squids would not change according to the exposure time and duration in the water.

From the above, the observation time for one squid was fixed at 20 minutes. After recording their behavior, the squid in the experiment tank was replaced by a new one from the holding tank sequentially, and this recording was continued from 22:00 to 04:00 the next day, before the sunrise.

One day before the experiment, the squids were caught by the same method employed by the red sea bream long line fishers and were stored in the holding tank, which was kept at the same water temperature as in the experiment tank for one day. The methods of hooking the squid to the model gear were the same ones used in the red sea bream long line fishery around Jeju Island: inserting the hook into the thin layer part of the mantle (hooked at mantle) or penetrating the funnel around the mouth (hooked at funnel). In the experiment a total of 13 squids were used, 7 squids were hooked at mantle and the other 6 squids were hooked at funnel. Their total length and weight are shown in Table 1.

Considering the lighting condition of actual

Table 1. Total length and weight of squids used in this study according to hooking position

\begin{tabular}{|c|c|c|c|c|c|c|c|}
\hline $\begin{array}{l}\text { Hooking } \\
\text { position }\end{array}$ & $\begin{array}{l}\text { Number } \\
\text { of squid }\end{array}$ & $\begin{array}{l}\text { Total } \\
\text { length } \\
(\mathrm{cm})\end{array}$ & $\begin{array}{l}\text { Weight } \\
(\mathrm{g})\end{array}$ & $\begin{array}{l}\text { Hooking } \\
\text { position }\end{array}$ & $\begin{array}{l}\text { Number } \\
\text { of squid }\end{array}$ & $\begin{array}{l}\text { Total } \\
\text { length } \\
(\mathrm{cm})\end{array}$ & $\begin{array}{c}\text { Weight } \\
\text { (g) }\end{array}$ \\
\hline \multirow[t]{8}{*}{ Mantle } & 1 & 25 & 100 & Funnel & 1 & 23 & 100 \\
\hline & 2 & 22 & 75 & & 2 & 20 & 60 \\
\hline & 3 & 23 & 75 & & 3 & 23 & 75 \\
\hline & 4 & 22 & 80 & & 4 & 24 & 100 \\
\hline & 5 & 24 & 100 & & 5 & 23 & 80 \\
\hline & 6 & 23 & 75 & & 6 & 24 & 110 \\
\hline & 7 & 24 & 100 & & - & - & - \\
\hline & Average & 23.3 & 86.4 & & Average & 22.8 & 87.5 \\
\hline
\end{tabular}


fishing situations, we used only one incandescent light bulb (TL-D Super $8032 \mathrm{~W}$, PHILIPS) to maintain the minimum intensity of illumination so that the camera could capture the scenes. The video recording was done with a video camera (DCRPC120, SONY) set on a tripod, $1 \mathrm{~m}$ in front of the tank. The experiment was observed from a separate room to make sure the movements of the squids were not disturbed. The video data recorded was converted into a $640 \times 480$ pixel AVI format video file using the capturing function on a computer. The movement tracks of the squids were displayed on the computer screen with still images at 0.25 second intervals and the coordinates were read by self-produced digitizing software.

The coordinates $P_{m}\left(x_{m}, z_{m}\right)$ read by a computer were applied on the definition where the upper left corner of the tank was the origin point $o_{m}\left(x_{o m}, z_{o m}\right)$. They were converted into the actual coordinates $P_{r}$ $\left(x_{r}, z_{r}\right)$ by the following equation:

$$
\left(\begin{array}{c}
x_{r} \\
z_{r}
\end{array}\right)=\left(\begin{array}{c}
\left(x_{m}-x_{o m}\right) C_{x} \\
\left(z_{m}-z_{o m}\right) C_{z}
\end{array}\right)
$$

Where $C_{x}$ and $C_{z}$ are the rates of the real lengths to the pixel numbers for the horizontal and vertical on the PC screen, respectively (Bae et al., 2011; Petrell et al., 1997).

\section{RESULT}

\section{Movement patterns}

The characteristics of the squid' s movements were observed from the video recordings. In the beginning, the squids acted as if they were trying to unhook themselves and the branch line hanging from the top of the tank remained strained. Afterwards, the squids swam in various directions and following different patterns, which resulted in the branch line becoming looser than in the

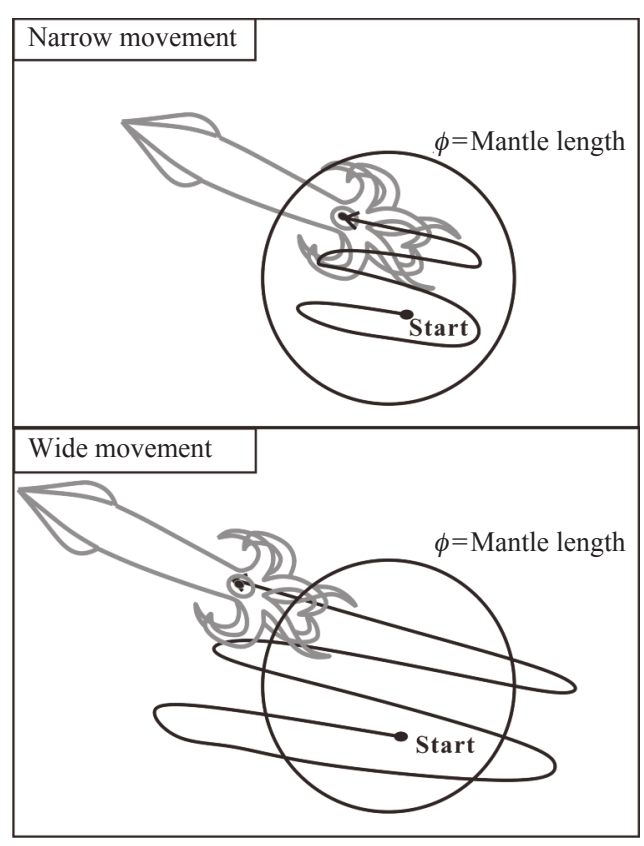

Fig. 2. Classification of movement range: narrow movement $(\mathrm{N})$ is defined as squid movement inside a circle within the diameter of its mantle length; wide movement $(\mathrm{W})$ is defined as movement that exceeds this circle. The circle shows the range within the diameter of the squid's mantle length.

Table 2. Classification of behavioral patterns observed during this study

\begin{tabular}{|c|c|}
\hline Pattern & Description \\
\hline PT1 & $\begin{array}{l}\text { The squid tried to remove the hook and pulled the line strongly. The branch line was stretched in this } \\
\text { behavioral pattern only. }\end{array}$ \\
\hline PT2 & The squid moved up and down periodically. \\
\hline РT3 & The squid moved horizontally while turning its body. \\
\hline PT4 & $\begin{array}{l}\text { The squid moved obliquely upward and downward and the speed of climbing was faster than that of } \\
\text { descending. }\end{array}$ \\
\hline PT5 & The squid kept its body axis horizontal while it moved vertically. \\
\hline
\end{tabular}




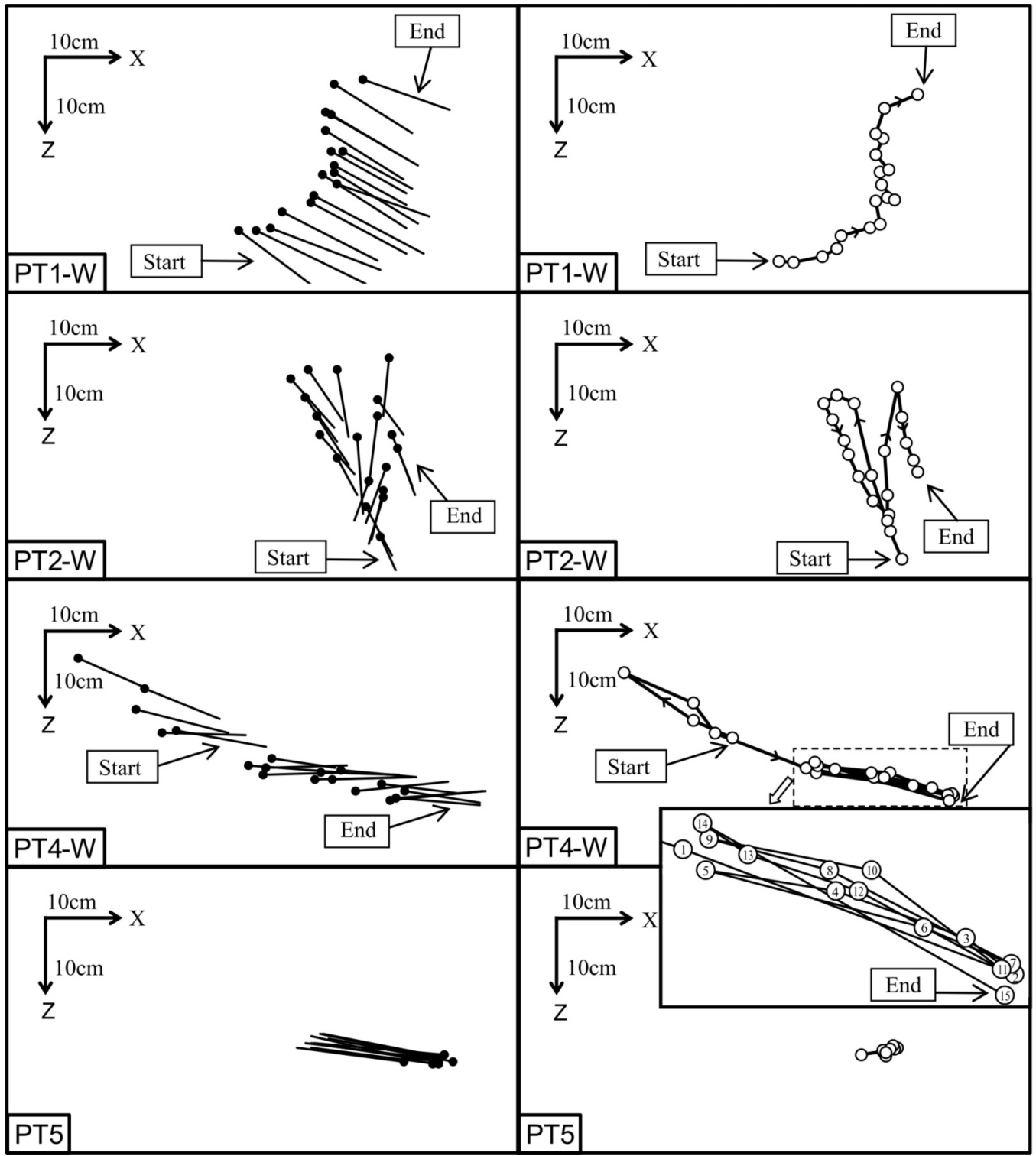

Fig. 3. Example of behavioral patterns of PT1-W, PT2-W, PT4-W and PT5 for 20 seconds. Left figures show the changes in body axis according to the time elapsed at 1-second intervals. In these figures, each line with a black filled circle shows the position of the mantle. Solid lines indicate body axis and the opposite end of the line shows the position of the funnel. Right figures show the track according to time elapsed at 1-second intervals. In these figures, the white circles show the center of the squid and lines show the moving track. The movement track of squid PT4-W shows a dotted box which expanded represents and enlarged part of the track, where the numbers indicate the sequence of the movements.

beginning. The series of squid's movements are shown in Table 2 and divided into 6 patterns ranging from PT1 to PT5 and ETC.
In addition, the movement patterns were divided into two types of, Wide (W) and Narrow (N), according to the range of the movement (Fig.2). 
Where, $\mathrm{W}$ is the movement in which the squids swam in a wider range than the circle which is shown, which has a diameter equivalent to the squid' s mantle length, and $\mathrm{N}$ is the movement where the squids swam within this circle.

Among all the patterns, PT1-W, PT2-W, PT4-W and PT5 showed their unique characteristics in the time series changes of their body axis and in their movement tracks and their examples are shown in Fig. 3, where the changes of their body axis are shown in the left and movement track are shown in the right. In these figures, the tip parts of the squid' $s$ mantles are represented by black circles, and the lines connecting the tip to one of the eyes show the body axis. In addition, the position of the squid, which is defined as the center between tip of the mantle and the one of the eyes, is shown with a white circle and the movement tracks are shown as a line connecting the circles. The arrows are showing the direction of the movements.

In PT1-W, when the squid moves, the branch line is strained and the body axis is heading towards the connecting point of the main line and the branch line. In PT2-W, though the body axis is tilted slightly, the squid moves up and down, and when it moves up, the movement direction and the body axis corresponds, and when the squid moves down, the axis and the direction of the movement are the opposite.

Moreover, though the squid moves up by moving its fins, it moves down by free falling and the climbing speed is faster than the descending one. In PT4-W, the squid swims almost horizontally along its body axis. In this case, the squid moves obliquely by water injection from its funnel (jet blast) and it moves back to the initial position without jet blast subsequently. When the squid moves up obliquely, the movement direction and the axis corresponded, and they are the opposite while descending. The climbing speed by the jet blast is faster than the speed when it drops back to its original position, and the averaged climbing speed of $21.5 \pm 1.9 \mathrm{~cm} / \mathrm{s}$ in PT4-W is faster than the speed of $8.4 \pm 1.4 \mathrm{~cm} / \mathrm{s}$ in $\mathrm{PT} 2-\mathrm{W}$ when propelled

Table 3. Appearance frequencies of the movement patterns of squids. $M$ and $F$ show hooking position of the squid at the mantle and funnel, respectively

\begin{tabular}{|c|c|c|c|c|c|c|c|c|c|c|c|}
\hline \multirow{2}{*}{$\begin{array}{c}\text { Squid } \\
\text { No }\end{array}$} & \multicolumn{11}{|c|}{ Behavioral frequencies (time (s) and percentage of total time (\%)) } \\
\hline & PT1-N & PT1-W & PT2-N & PT2-W & PT3-N & PT3-W & PT4-N & PT4-W & PT5 & ETC & Total \\
\hline M1 & - & - & $1114(92.8)$ & $46(3.8)$ & - & - & $24(2.0)$ & - & - & $16(1.4)$ & $1200(100)$ \\
\hline M2 & - & $52(4.3)$ & $721(60.1)$ & $360(30.0)$ & - & - & $10(0.8)$ & $2(0.2)$ & - & $55(4.6)$ & $1200(100)$ \\
\hline M3 & - & - & $1200(100)$ & - & - & - & - & - & - & - & $1200(100)$ \\
\hline M4 & $33(2.8)$ & $31(2.6)$ & $895(74.5)$ & - & $19(1.6)$ & $69(5.8)$ & - & $3(0.2)$ & $134(11.1)$ & $16(1.4)$ & $1200(100)$ \\
\hline M5 & - & $21(1.8)$ & $643(53.6)$ & $298(24.8)$ & - & - & - & $18(1.5)$ & - & $220(18.3)$ & $1200(100)$ \\
\hline M6 & $94(7.8$ & $46(3.9)$ & $1060(88.3)$ & - & - & - & - & - & - & - & $1200(100)$ \\
\hline M7 & $62(5.2)$ & $50(4.2)$ & 1065 (88.7) & - & - & - & - & - & - & 23 (1.9) & $1200(100)$ \\
\hline Total & $189(2.3)$ & $200(2.4)$ & $6698(79.8)$ & $704(8.5)$ & $19(0.2)$ & $69(0.8)$ & $34(0.4)$ & $23(0.3)$ & $134(1.5)$ & $330(3.8)$ & $8400(100)$ \\
\hline $\mathrm{F} 1$ & $4(1.2)$ & $(06)$ & $21(1.8)$ & $700(58$. & - & - & - & - & $250(20.8)$ & $208(17.3)$ & \\
\hline F2 & $83(6.9)$ & $21(1.8)$ & $408(34.0)$ & $366(30$ & - & - & - & - & $234(19.5)$ & $88(7.3)$ & $1200(100)$ \\
\hline F3 & - & $22(1.8)$ & 415 (34.6) & $319(26.6)$ & - & - & - & - & $316(26.3)$ & $128(10.7)$ & $1200(100)$ \\
\hline F4 & 35 (2.9) & $23(1.9)$ & $267(22.3)$ & $745(62.1)$ & - & $14(1.2)$ & - & - & $55(4.6)$ & $61(5.0)$ & $1200(100)$ \\
\hline F5 & - & $8(0.7)$ & 908 (75.7) & $245(20.4)$ & - & $10(0.8)$ & - & - & - & $29(2.4)$ & $1200(100)$ \\
\hline F6 & $83(6.9)$ & - & 470 (39.2) & $274(22.8)$ & 159 (13.3) & - & - & - & - & $214(17.8)$ & $1200(100)$ \\
\hline Total & $215(3.0)$ & $81(1.1)$ & 2489 (34.6) & $2649(36.8)$ & $159(2.2)$ & $24(0.3)$ & - & - & 855 (11.9) & $536(7.4)$ & $7200(100)$ \\
\hline
\end{tabular}


by fin movements. As described above, the movement direction, and the way of swimming and the speed were absolutely different between PT2-W and PT4-W. In PT5, while the squid maintains its position with its body axis almost parallel, movements of the fins and the arms are observed.

In Table 3, the appearance frequencies of PT1 to ETC according to the hooking position are shown as the ratio of the time duration of appearance to the total observation times.

In PT1 and PT3, the movements both by hooked at mantle and hooked at funnel were appeared very few. In PT2, the movements by both hooking methods were numerous. In PT4, though the movements by hooked at mantle were observed, the movement by hooked at funnel was not. In PT5 and ETC, the movements by hooked at funnel were observed more than those by hooked at mantle.

By hooked at mantle, PT2 was observed in 7402 seconds out of the total recording time of 8400 seconds of 7 squids and the appearance frequency was $88 \%$. In addition, $90 \%$ of the PT2 was categorized in PT2-N and PT2-W, which is the most typical movement pattern by hooked at mantle.

On the other hand, by hooked at funnel, PT2 was observed in 5138 seconds out of the total recording time of 7200 seconds of 6 squids and the appearance frequency was $71 \%$. In this PT2, PT2$\mathrm{N}$ and PT2-W appeared almost evenly and PT2-N and PT2-W were the most typical movement patterns in contrast to the results by hooked at funnel. In addition, PT5 was observed in more than $10 \%$ and this is the typical characteristic which is different from hooked at mantle.

Examples of the squid's movement tracks according to elapsed time for PT2-N (hooked at mantle) and PT2-N, PT2-W (hooked at funnel), which show the typical movement patterns are shown in Fig. 4. In these figures, though the periodical movement is not clear by hooked at mantle and hooked at funnel in PT2-N, the periodical horizontal and vertical movement with comparatively larger amplitude by hooked at funnel in PT2-W is clear because of the wider movement range.

On the other hand, when comparing the bait hooking points between hooked at mantle and hooked at funnel, the fish caught by hooked at
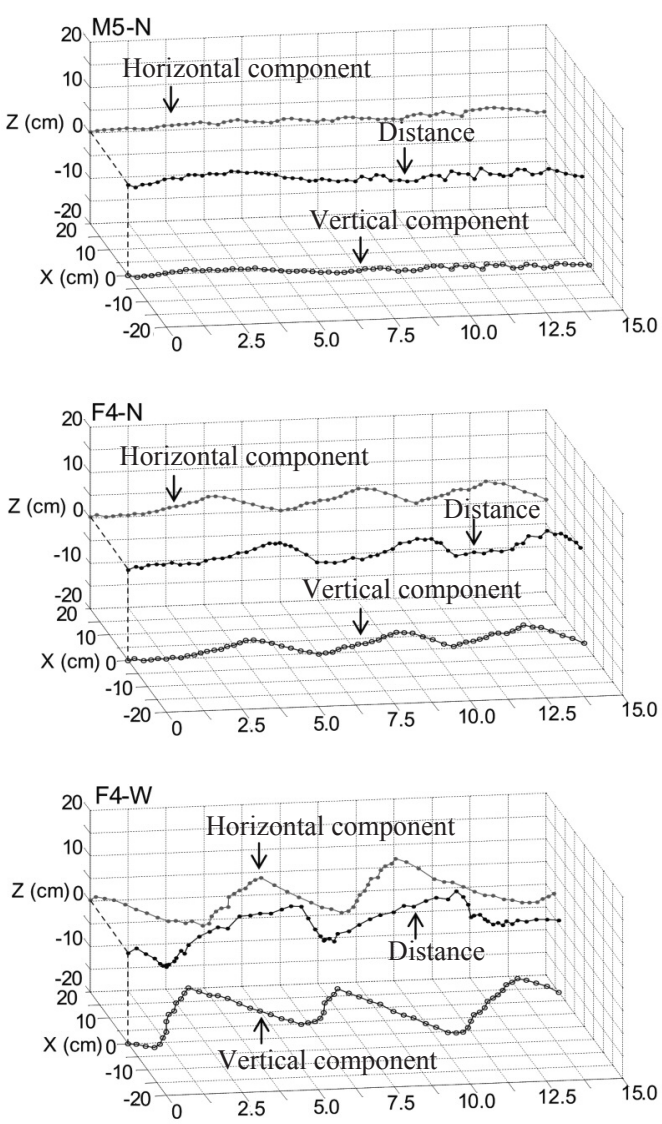

Fig. 4. Changes in the squid's horizontal and vertical components of position and distance from the start according to elapsed time. The periodicity of the wide movement when it was hooked at funnel was much clearer than when hooked at mantle. 
funnel were more numerous than by hooked at mantle according to the fisher's reports in Jeju Island. Based on this fact, we concluded that the typical and most effective movement of squid bait used to catch red sea breams is similar to those shown by the periodical movements of PT2-W by hooked at funnel, in which the amplitude is larger and the periodicity of the movement of PT2-W is analyzed by calculations of the dominant frequency and amplitude in this study.

\section{Movement Periodicity}

According to the Fast Fourier Transform (FFT) method, the horizontal components $A_{x_{f N}} \mathrm{~s}$ and the vertical components $A_{z_{f N}}$ s of the movement amplitudes of squids at the fundamental frequency $f_{B}$ and its integer multiple frequencies $A_{f_{N}}$ s are calculated from the horizontal components $x_{r} \mathrm{~s}$ and vertical components $z_{r} \mathrm{~s}$ of the movement tracks, and the compositions $A_{f_{N}}$ of their amplitudes are obtained by the following equation:

$$
A_{f_{N}}=\sqrt{\left(A_{x_{N}}\right)^{2}+\left(A_{z_{N}}\right)^{2}}
$$

All the time durations which are necessary to explain one movement in PT2-W, which are confirmed when the points of movement tracks are read from the video records, is longer than 1 second, thus the maximum frequency was set at $2 \mathrm{~Hz}$ for the analysis. When this maximum frequency is substituted into the equation as follow, which derives Nyquist frequency $f_{n}$, the data interval $\tau$ became 0.25 seconds. Moreover, the data length was set at 8 seconds, thus the analyzable lowest frequency is equal to the fundamental frequency $f_{B}$ of $0.125 \mathrm{~Hz}$.

$$
f_{n}=\frac{1}{2 \tau}
$$

In the frequency analysis, the time durations of 10.25 seconds in which the continuous coordinates can be read, were set as the analysis targets and the data interval was set at 0.25 seconds, thus the number of one data-set was 41 . The movement amplitudes at were calculated from the continuous 32 data of the 41 data in one data-set and the average $\overline{A_{x_{f v}}}, \overline{A_{z_{V}}}$ and $\overline{A_{f N}}$ were calculated by their 10 amplitudes respectively, which were obtained from 32 continuous data where the beginning time was delayed by 0.25 seconds.

The time series movements categorized from PT1 to ETC are shown in Fig. 5. In PT2-W of them, particularly the continuous 10.25 seconds data sets (dotted line squares) in which the movement tracks can be read, were used in the actual frequency analysis. In the figure, though a lot of data seemed to be analyzed, the data length used for the analysis was 184.5 seconds of the total appearance time of 1,704 seconds by 4 squids

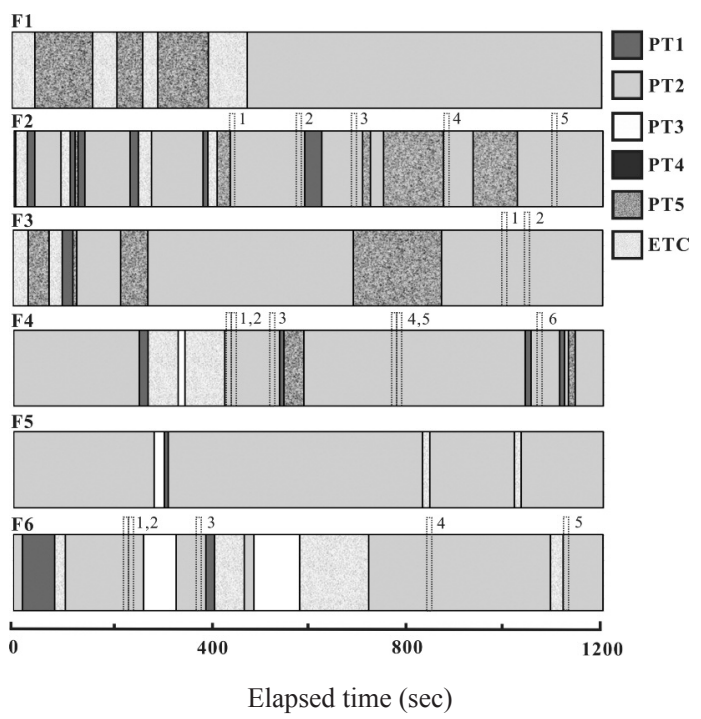

Fig. 5. Appearance frequency of movement patterns when the squid was hooked at funnel. Analyzed parts are shown as dotted squares with their assigned numbers. 
because the recording condition was not adequate for reading and unreadable recordings were included.

The spectrums obtained from this analysis are shown in Fig. 6. The numbers here are correspondent to the number of data set in Fig. 5.

The dominant frequencies that represent the maximum values of the obtained amplitudes are in the range of $0.125 \mathrm{~Hz}$ to $0.25 \mathrm{~Hz}$. The frequency was $85 \%$ at $0.125 \mathrm{~Hz}$, and $15 \%$ at $0.25 \mathrm{~Hz}$ and they were mainly concentrated at the minimum analyzable frequency of $0.125 \mathrm{~Hz}$.

The horizontal components of the movement amplitude at the dominant frequency of $0.125 \mathrm{~Hz}$
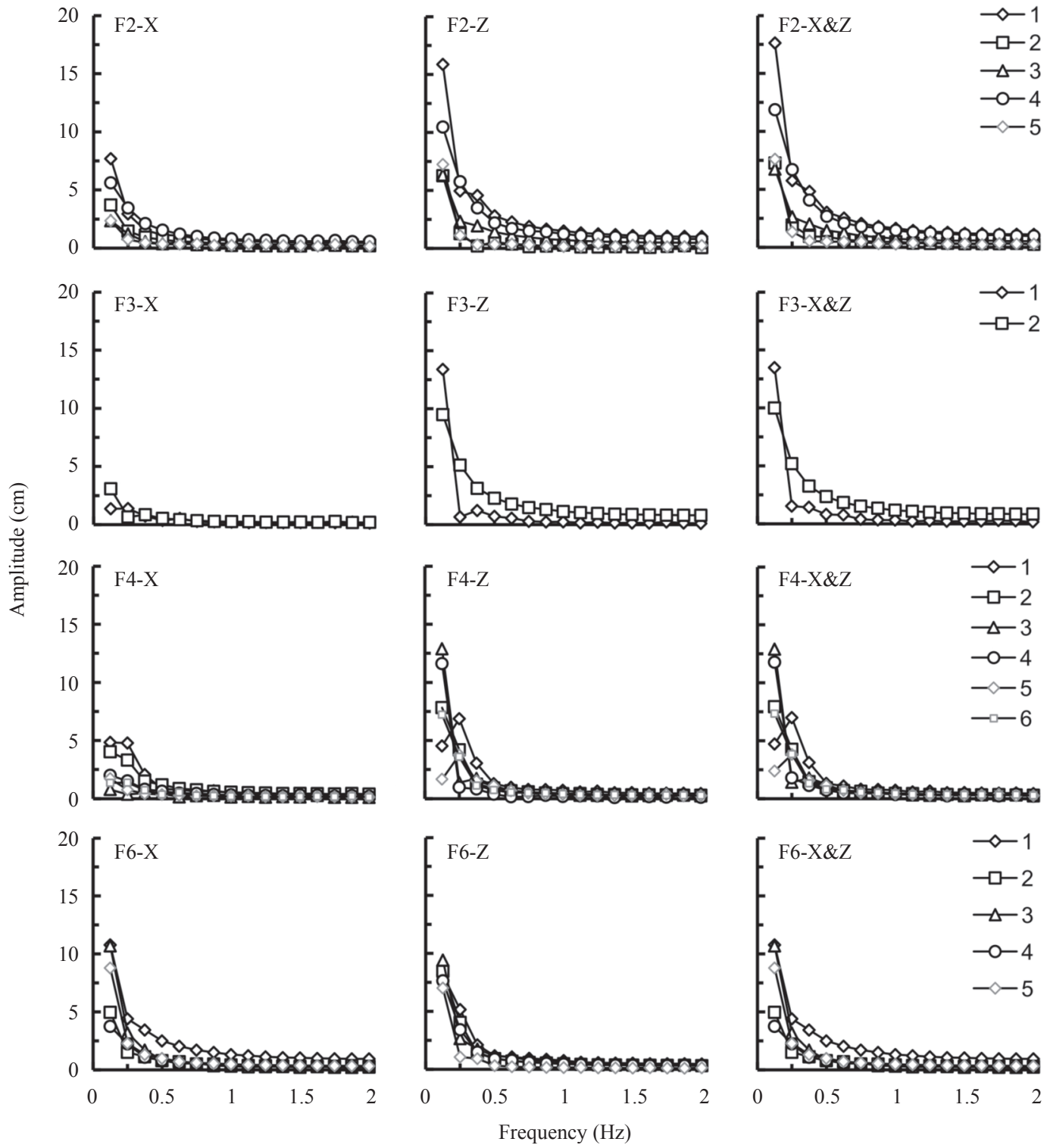

Fig. 6. Averaged amplitudes of horizontal and vertical components and their compositions for 10 sample times obtained from FFT analysis of squid movement. Numbers with symbols are assigned by analyzed data sets shown in Fig. 5. 
ranged from $0.8 \mathrm{~cm}$ to $10.8 \mathrm{~cm}$ and the average was $4.8 \pm 3.1 \mathrm{~cm}$. In addition, the vertical components of the movement amplitude ranged from $6.3 \mathrm{~cm}$ to $15.9 \mathrm{~cm}$ and the average was $9.3 \pm 2.7 \mathrm{~cm}$. The movement amplitudes ranged from $6.8 \mathrm{~cm}$ to $17.6 \mathrm{~cm}$ and the average was $10.8 \pm 3.0 \mathrm{~cm}$.

Based on these results, the averaged movement direction is estimated to be tilted 63 degrees from the horizontal axis, and the movements in PT2-W are estimated to exceed more vertically than horizontally.

\section{DISCUSSION}

In this study, all experiments were carried out while the water circulation was suspended in the water tank. Of course, though there must be differences of squid' $s$ movements according to the current conditions in the actual long line fishery in Jeju Island, most fishers choose the time when the drift of the tide is suspended. Therefore, the conditions in this experiment reflect the actual fishing situations of red sea bream attracted by the movements of live squids.

During the observations of the video recording, we found that squid movements is periodical represented in PT2 by hooked at funnel, and the amplitude of this movement was almost $15 \mathrm{~cm}$ in the maximum and the cycle was 8.2 seconds $(0.122 \mathrm{~Hz})$. In addition, the movement direction was slightly tilted from the vertical axis. These facts are almost corresponded to the analysis results from this experiment. However, since the squid' $s$ climbing speed by fin movement and the jet blast are faster than the descending speed after the climbing and the representative movements cannot be explained simply as periodical movements, there may be movements which cannot be explained by the movement cycle and amplitude. Thus these points need to be examined in the future issues. The movements of squids were divided into 6 patterns including ETC in this study, and the appearance frequency of PT2, where the branch line and hook cannot touch the squid' $\mathrm{s}$ body and the movement was not affected. This can be the reason why the movement amplitude by hooked at mantle was smaller than by hooked at funnel in PT2. In other words, by hooked at mantle, the branch line is attached on the upper of the mantle and the range where the squid can move up without touch is narrow. On the other hand, by hooked at funnel, moving up with angles tilted slightly to vertical direction will allow the squid a wide moving area, which will result in less touching of branch line. From the above, hooked at funnel can provide a better visual stimulus effectively than hooked at mantle, and it has this advantage for fishing. Fishers in Jeju Island have thought that red sea breams tend to eat from mantle hooked squids and that hooked at funnel is more effective for fishing because it is more difficult to be recognized than hooked at mantle. Although the view points are different, the better way of hooking corresponds with the results.

The most typical movement of squids in this study shows the amplitude of $10.8 \mathrm{~cm}$ at the dominant frequency of $0.125 \mathrm{~Hz}$ and this is equivalent to a speed of $5.4 \mathrm{~cm} / \mathrm{s}$. Tamura (1952) explained that a movement slower than $5 \mathrm{~cm} / \mathrm{s}$ can be considered as the static movement in his experiment with sea basses. For sea bass, the representative movement of squids or movement with the higher frequency of the squids can be said to induce the predatory activity. In addition, this can be applied to red sea breams, which are found in the same suborder. On the other hand, in this study, though the typical movements of squids 
were assumed to induce the predatory activities of red sea breams which are the fishing target species, our other study with red sea breams must investigate if the assumptions were true and if the typical movement explained in this study is the best visual stimulus from the red sea breams.

Based on the results from this experiment, the movement of red sea breams to the periodical movement with various frequencies higher than $0.125 \mathrm{~Hz}$ and the best frequency of target movement to induce the predatory activities will be clarified by our further research. In addition, the relationship to the typical movement of squids will be investigated.

\section{ACKNOWLEDGMENT}

We thank Woo Young Kang, the captain of Dongah Fishing vessel for his help with capturing the squids used in the experiment. For the help with the water tank experiments, we thank Young Don Lee, the head of the Marine \& Environmental Research Institute of Jeju National University.

\section{REFERENCES}

Bae JH, Lee KH, Shin JG, Yang YS and Lee JH. 2011. Measurement of swimming ability of silver fish (Plecoglossus altivelis) using a Particle Imaging Velocimetry. J Kor Soc Fish Tech 47, 411-418.

Lee BG, Park SE and Kim JK. 1985. An introduction to coastal fishery. Taehwa, $108-111$.

NFRDI (National Fisheries Research \& Development Institute). 2000. Commercial mollusks from the fresh water and continental shelf in Korea. Kudeok, Busan, 176.

Okada K. 1965. On the feeding activity of the young sea bream, Chrysophrys Major tenmminck et schlegel, in the Yellow Sea. Nippon Suisan Gakkaishi 31, 999 -1005 .

Petrell RJ, Shi X, Ward RK, Naiberg A and Savage CR. 1997. Determining fish size and swimming speed in cages and tanks using simple video techniques. Aquaculture Engineering 16, 63-84.

Sudo H, Azuma M and Azeta M. 1987. Diel changes in predator-prey relationship between red sea bream and gammaridean amphipods in Shijiki Bay. Nippon Suisan Gakkaishi 53, $1567-1575$.

Tamura T. 1952. On the senses of food-searching in Lateobabrax japonicus. Nippon Suisan Gakkaishi $17,296-300$.

2013년 2월 5일 접수

2013년 5월 29일 1차 수정

2013년 7월 5일 2차 수정

2013년 7월 10일 수리 